\title{
Literatura Atlântica: notas sobre o comparatismo em língua portuguesa
}

Atlantic literature: Notes on comparativism in

\author{
Portuguese
}

Lisa Carvalho Vasconcellos*

RESUMO: CONSTATANDO A INADEQUAÇÃO DO TERMO LUSOFONIA - PALAVRA CARREGADA POR ECOS COLONIALISTAS E AUTORITÁRIOS - PARA DEFINIR O ESTUDO DAS LITERATURAS LUSO-AFROBRASILEIRAS, O ARTIGO PROPÕE UMA NOVA POSSIBILIDADE CONCEITUAL PARA O COMPARATISMO EM LÍNGUA PORTUGUESA: A LITERATURA ATLÂNTICA. O TERMO, INSPIRADO EM RECENTES ESTUDOS HISTORIOGRÁFICOS E DAS CIÊNCIAS SOCIAIS, TOMA O MAR COMO METÁFORA PARA AS TROCAS CULTURAIS NÃO-HIERÁRQUICAS QUE ACONTECERAM E CONTINUAM A ACONTECER ENTRE OS PAÍSES DE COLONIZAÇÃO PORTUGUESA ESPALHADOS EM TRÊS CONTINENTES.

ABSTRACT: ACKNOWLEDGING THE INADEQUACY OF THE TERM LUSOPHONY - A WORD THAT TODAY STILL CARRIES COLONIAL ECHOES - TO DEFINE THE STUDY OF LITERATURES FROM BRAZIL, PORTUGAL AND AFRICA IN COMPARISON, THE ARTICLE PROPOSES A NEW CONCEPTUAL POSSIBILITY FOR THE COMPARATISM BETWEEN COUNTRIES THAT SPEAK PORTUGUESE: WE CALL IT ATLANTIC LITERATURE. THIS EXPRESSION, INSPIRED IN RECENT SOCIAL AND HISTORICAL STUDIES, TAKES THE SEA AS A METAPHOR TO THE NON-HIERARCHICAL EXCHANGES THAT TOOK AND STILL TAKE PLACE BETWEEN COUNTRIES OF PORTUGUESE COLONIZATION.

PALAVRAS-CHAVE: LUSOFONIA, LITERATURA ATLÂNTICA, COMPARATISMO KEYWORDS: LUSOPHONY, ATLANTIC LITERATURE, COMPARATISM

* Bacharel em Letras pela Universidade Federal de Minas Gerais UFMG (2003). Mestre em Literatura Brasileira (2005) pela mesma instituição, defendendo dissertação sobre a obra de Guimarães Rosa. Doutora em Literatura Comparada pela USP (2011) É autora dos livros Vertigens do eu: autoria, alteridade e autobiografia na obra de Fernando Pessoa (Relicário, 2013) e Figurações da Leitura: um estudo sobre o papel do narratário em Grande sertão: veredas (Scortecci, 2008), que foi por sua vez ganhador do II Prêmio de Literatura UBE/ Scortecci 2007. Desenvolve pesquisa sobre literatura luso-afro-brasileira do século XX na modalidade PRODOC (Pós-Doutorado) pela Pós-Graduação de Literatura e Cultura do Instituto de Letras da Universidade Federal da Bahia (UFBA). 
usofonia, termo que surge pela agregação de dois radicais conhecidos: luso, português, e fonia, falante. Lusófonos são todos aqueles, nos explica o Dicionário Houaiss da Lingua Portuguesa, que falam português como língua materna ou não. A lusofonia, continua a explicação, "abrange, além de Portugal, os países de colonização portuguesa, a saber: Brasil, Moçambique, Angola, Cabo Verde, Guiné-Bissau, São Tomé e Príncipe; e partes das populações de Goa, Damão e Macau e Timor" (HOUAISS, 2008, p. 1793, adaptado). No âmbito dos estudos literários, o campo da lusofonia é aquele no qual as expressões artísticas desses diferentes lugares são estudadas comparativamente.

Embora os estudos de Literatura Portuguesa no Brasil e de Literatura Brasileira em Portugal ${ }^{1}$ já sejam tradicionais, a ideia de lusofonia, como campo onde se incorporam também as literaturas da África, Ásia e Oceania, é bastante recente, tendo ganhado força na medida em que as ex-colônias, depois de independentes, consolidavam cada uma a sua literatura nacional. Pode-se dizer que a lusofonia, apesar das suas especificidades (a maior delas é a noção de que se está lidando com países que compartilham uma mesma língua²) se insere no âmbito maior dos estudos de Literatura Comparada, e com ele compartilha uma série de pressupostos que devem ser mencionados aqui.

Tânia Franco Carvalhal nos lembra que comparar objetos distintos como uma forma de colocá-los em perspectiva ou ainda de fundamentar juízos de valor a respeito dos mesmos é uma forma básica de conhecimento humano, que serve de metodologia para inúmeras áreas da ciência. Historicamente, entretanto, o cotejamento de obras e realizações de épocas e lugares diferentes teve um papel específico, para além de funcionar como puro método científico. Não podemos esquecer que a Literatura Comparada despontou como disciplina em meados do século XIX, não por acaso, em período concomitante à ascensão da atual configuração política dos Estados nacionais modernos, mais ou menos como os conhecemos hoje. Dentro de um contexto pautado pelas preocupações com o estabelecimento da soberania nacional, o comparatismo foi uma das estratégias empregadas na busca de possíveis

\footnotetext{
${ }^{1}$ Dois bons depoimentos sobre o surgimento das cátedras de Literatura Portuguesa no Brasil e de Literatura Brasileira e Africana em Portugal são respectivamente "O magistério de literatura portuguesa" de Cleonice Berardinelli e "Ensinar literatura brasileira em Portugal" de Abel Barros Baptista.

${ }^{2}$ Abel Barros Baptista tem um interessante artigo já mencionado aqui, "Ensinar literatura brasileira em Portugal", no qual discute as ambiguidades dessa proximidade.
} 
matrizes para as produções literárias de cada país. Determinar empréstimos, estabelecer fontes e identificar influências no que diz respeito a temas artísticos e técnicas de composição - metodologias básicas no âmbito da Literatura Comparada tradicional - foram procedimentos empregados por autores e críticos para mapear a cultura de um país e estabelecer, a partir de uma noção romântica de origem, as raízes culturais e artísticas dos novos Estados.

Em seus primórdios, a Literatura Comparada esteve, então, intimamente associada às práticas de poder e dominação, uma vez que sua constituição e estabelecimento se deram em meio a um projeto político claro, de ressonância histórica e também militar, tendo sido usada, no limite, como forma de legitimar a própria ideia de uma literatura nacional, parte do patrimônio simbólico de uma nação, assim como seu território, suas riquezas naturais ou direitos de primazia (autodeclarados) sobre povos vizinhos ou de além mar. Resta saber como essa metodologia foi empregada no que diz respeito à literatura dos países lusófonos, que são os que nos dizem respeito mais diretamente neste artigo. Para discutir isso e assentar algumas das bases da argumentação que propomos, convém analisar um exemplo local, o primeiro trabalho de Literatura Comparada publicado no Brasil ainda no início do século XX, intitulado Machado de Assis - influências inglesas.

No livro, como o próprio título anuncia, Eugênio Gomes procura mostrar, a partir de um extenso cotejamento entre a obra do escritor brasileiro e a tradição inglesa, como o trabalho de Machado de Assis é devedor das leituras de Swift, Shakespeare e Sterne, principalmente. É importante ressaltar que, com isso, Gomes procurava valorizar o trabalho de Machado, demonstrando que, ao contrário do que foi acusado, ele não se deixou influenciar pelos modismos franceses da época, mas se ligou a uma tradição muito mais antiga e venerável, a do humor filosófico inglês. Ou seja, com base em uma noção verticalizada de influência, devedora do comparatismo tradicional, Gomes fez uma análise na qual hierarquizou autores e obras de acordo com sua distância de uma suposta origem. Dentro desse sistema de valores, Machado merecia, segundo ele, um lugar privilegiado, uma vez que se ligava diretamente a pretéritas fontes europeias, e não aos autores franceses modernos, considerados, àquela altura, como autores de menor importância e autenticidade nacional.

O exemplo nos mostra que, para a literatura brasileira, o comparatismo tradicional é uma ferramenta, no mínimo, ambígua. Afinal, se essa metodologia 
se presta a valorizar o trabalho de um dos nossos maiores escritores é só na medida em que este se aproxima de um modelo europeu, distante da cultura brasileira no tempo e no espaço. O mesmo talvez possa ser dito sobre o comparatismo no que concerne à literatura das demais ex-colônias portuguesas. Como o Brasil, também Moçambique, Angola, Cabo Verde, Guiné-Bissau, São Tomé e Príncipe, Goa, Damão e Macau e Timor são herdeiros de uma língua e de uma tradição europeias. Dentro de um campo que se elaborou historicamente em torno de uma noção eurocêntrica e verticalizada de influência e preponderância linguística, os escritores desses países estarão sujeitos a ser continuamente avaliados a partir de um único vetor - aquele que transmite, do passado para o presente, do estrangeiro para o nacional, sempre em via de mão única, os valores de cultura e civilização com os quais, até hoje, há identificação e desejo.

Ora, essa é uma perspectiva que hoje dificilmente convence críticos e estudiosos de literatura em geral. A própria Literatura Comparada há muito relativizou as noções clássicas em torno das quais se erigiu enquanto disciplina e partiu em busca de outros paradigmas mais abertos à diversidade e menos autoritários, especialmente no que diz respeito às possíveis relações entre diferentes textos e autores ${ }^{3}$. É preciso reconhecer, entretanto, que é à noção descrita nos parágrafos anteriores que subjaz o conceito de lusofonia. O próprio vocábulo - constituído a partir da derivação do radical luso, ou seja, elegendo Portugal como centro, no caso, de língua e cultura, mas também da política - implica necessariamente em uma visão hierárquica e metropolitana no que diz respeito às relações que se estabeleceram e continuam a se estabelecer entre as muitas manifestações literárias produzidas nos países de língua portuguesa.

No campo das literaturas produzidas nesse idioma, a cada dia, um número maior de estudiosos e pesquisadores manifesta a sua insatisfação com os pressupostos da lusofonia e explicita a necessidade de um novo discurso que dê conta das múltiplas conexões culturais que existem entre países como Brasil, Angola e Portugal, por exemplo. É isso o que faz o último livro do professor - radicado nos Estados Unidos - Fernando Arenas, Lusophone Africa:

\footnotetext{
${ }^{3}$ Essa mudança pode ser facilmente constatada pela leitura do livro Literatura comparada: textos fundadores, organizado por Eduardo Coutinho e Tania Franco Carvalhal.
} 
beyond Independence (2011), que, em seu capítulo inicial, defende que as relações entre as literaturas de Portugal e de suas ex-colônias africanas deva ser pensada a partir de outros vetores que não o tradicional (e pleno de significados) norte-sul. E é isso também o que defende, entre outros termos, o crítico e pesquisador brasileiro Benjamin Abdala Jr. (2002) quando propõe a lógica da multiplicidade como paradigma para pensar as trocas humanas e culturais que se deram, ao longo de séculos, entre Brasil, Portugal e África.

Com base em demandas desse tipo é que queremos propor aqui um outro campo de atuação, uma outra formulação conceitual com a qual seja possível pensar, em bases distintas, as manifestações culturais dos países de língua portuguesa: a Literatura Atlântica. Seria uma outra maneira de pensar a lusofonia que não seja pautada pelas noções de fonte e influência, origem e cópia, centro e periferia, mas que tente contemplar as relações existentes entre as literaturas dos diferentes países de língua portuguesa a partir da multiplicidade de caminhos, de uma via em que não há hierarquias, modelos ou tutores a seguir. A referência ao mar como uma referência ao mesmo tempo concreta, geográfica ${ }^{4}$, mas também simbólica e especulativa, uma vez que incorpora a si a horizontalidade desterritorializada das águas, em meio às quais (histórica, política e poeticamente) as trocas culturais se processaram desfazendo os roteiros e predeterminações que os poderes colonial e neocolonial impunham.

A expressão, como se pode notar, é claramente inspirada pela historiografia recente, que nos últimos anos estabeleceu um campo de pesquisa novo sobre o qual gostaríamos de discorrer rapidamente antes de prosseguir. Vem se firmando em meio aos estudos históricos um campo de pesquisa denominado de História Atlântica. Seu corpus de trabalho são justamente as relações e trocas que enformaram o intercâmbio euro-afro-americano através dos séculos. Essa nova categoria de análise histórica foi inicialmente proposta pelo professor e pesquisador Jack P. Greene, da Universidade de Jonhs Hopkins, como uma forma de entender alguns dos movimentos chave para a formação do mundo moderno. Comércio triangular, tráfico negreiro, migrações de povos e culturas, são alguns dos temas que ligaram Europa, África e Américas

\footnotetext{
${ }^{4}$ É preciso deixar claro que a Literatura Atlântica não se apresenta como possibilidade de leitura das culturas e manifestações literárias dos países banhados pelo oceano Atlântico. Como se verá, o nome toma de empréstimo uma formulação recente desenvolvida no âmbito da história e da ciência política, sem contudo ter de prender-se, exclusivamente, a referências e fronteiras geográficas.
} 
que caem sob o interesse da História Atlântica. O modelo teórico procurou, em resumo,

Fugir do molde imperial ou nacionalista para atravessar divisas e fronteiras, para estudar o movimento das pessoas, de animais, de plantas e mercadorias numa escala não apenas Atlântica, mas global, para reconstruir o ir e vir de ideias, estilos, modas e artes. A intenção foi reunir estudiosos de várias disciplinas que contribuíram para a criação de uma nova perspectiva e uma aproximação original à riqueza de facetas do Atlântico e da interconectividade dos povos nos continentes banhados por suas ondas (RUSSEL-WOOD, 2009, p. 19).

No Brasil, a História Atlântica tem sido objeto dos trabalhos, dentre outros, de Luiz Felipe de Alencastro e Roquinaldo Ferreira, curiosamente ambos professores em universidades estrangeiras (Sorbonne e Brown University, respectivamente). Ambos procuraram pensar o papel do Brasil na intrincada teia de relações que teve o Atlântico como palco, forçando os limites de uma historiografia forjada, muitas vezes, em torno de critérios nacionais ou coloniais que apenas se apresentavam como entraves metodológicos (e também ideológicos) para o estudo detido da formação múltipla e híbrida das sociedades - e também, é claro, das culturas e literaturas - de países como Portugal, Brasil e Angola, entre outros.

Inspirados nesse modo de propor o problema, trabalhamos com a ideia de que também na área de Letras é possível desenvolver um campo de estudos tendo o Atlântico como referência espacial e simbólica. A ele caberia pesquisar, não os eventos históricos, mas a cultura, a literatura e a memória política que se construiu a partir do oceano e das trocas por ele propiciadas. Não queremos com isso propor um campo colado àquele inaugurado pelos historiadores, mesmo porque as preocupações desses últimos se focam, nesse caso, principalmente entre os anos 1500 e 1800 . O que gostaríamos de fazer é aproveitar o caminho palmilhado pelos historiadores dentro de uma outra esfera - a das trocas atuais que os estudiosos podem fazer.

Como foi feito sobre o âmbito da história, a Literatura Atlântica tentará contemplar as relações simbólicas que se estabeleceram entre os países de língua portuguesa levando em conta o papel múltiplo que o Atlântico exerceu sobre eles. Para Portugal, Brasil e vários dos países africanos - Angola, São Tomé e Príncipe, Cabo Verde e Guiné-Bissau - o Oceano Atlântico teve um 
papel complexo e ambíguo. Durante séculos, ele foi ao mesmo tempo litoral, fronteira, limite geográfico, representação do perigo, do desconhecido e da morte; do fim último, portanto. Eventualmente, ele era também caminho, passagem, lugar de encontro e trocas (comerciais e culturais), mas também local privilegiado das práticas de dominação colonial, de tráfico de escravos, das migrações forçadas, da guerra e do exílio. Nesse sentido, ele, o Atlântico, é o elemento comum que, mais do que a partilha da língua do colonizador, une e ao mesmo tempo separa Brasil, Portugal e a África, sendo parte decisiva do legado comum que essas nações construíram. Levar em conta a especificidade do diálogo que se estabeleceu, através das águas, entre os povos e suas produções simbólicas talvez possa iluminar aspectos históricos, políticos e estéticos até então pouco considerados quando se lança um olhar comparatista sobre suas trajetórias.

Ainda nessa perspectiva, o Oceano Atlântico pode ser compreendido como - para falarmos com Deleuze e Guattari - um plano atravessado por múltiplas linhas de fuga. Não há início ou fim, origem ou telos determinado; não há ordenamento que não seja instável e suscetível a várias influências e transformações. É impossível dizer que ele parte da Europa ou a ela retorna. Assim como, conforme propomos, se caracterizam as relações literárias e culturais estabelecidas entre Portugal, Brasil e a costa ocidental da África. Não há ponto de partida que não seja, ele mesmo, reversível e mutável ${ }^{5}$.

Uma entre as muitas potencialidades abertas pela Literatura Atlântica pode ser vista no estudo, ainda bastante incipiente no campo intelectual de língua portuguesa, dos textos ficcionais e dos testemunhos desenvolvidos a partir das prisões políticas que se disseminaram, de modo semelhante, por Portugal, Brasil e muitos países da costa Africana (Angola, Guiné-Bissau e África do Sul, para mencionarmos apenas alguns exemplos), a partir do que cha-

\footnotetext{
${ }^{5}$ Não se deve confundir a concepção aqui proposta com a noção de "atlantismo" cunhada por Irene Ramalho Santos. No livro Poetas do Atlântico, a professora e pesquisadora portuguesa vê no mar e seus motivos um forte elemento de ligação entre a lírica portuguesa (em especial Fernando Pessoa) e alguns dos principais poetas anglo-americanos, como Walt Whitman, T. S. Eliot e Hart Crane. Daí o Atlântico Norte ser tomado nesse livro como metáfora e referência fundamental para as relações intertextuais que se estabeleceram entre escritores de diferentes continentes. Como se vê, o que orienta o seu esforço interpretativo são ainda categorias que hierarquizam as trocas culturais, além de enxergá-las apenas no âmbito propriamente literário, não levando em conta a dimensão histórica, política e social dessas relações literárias.
} 
mamos aqui de "ilhas-prisão", experiências concentracionárias desenvolvidas em muitos dos países mencionados a partir do uso sistemático de ilhas como território punitivo (baseado no isolamento e na aniquilação sistemática de opositores), e em torno das quais se formou vasta produção cultural de memória e resistência política.

Como é bastante conhecido, ao longo dos séculos, muitas ilhas foram mantidas como prisões especiais pelo governo português e, mais tarde, pelos governos brasileiros e vários Estados africanos. Apenas para lembrar algumas: Ilha Grande, Ilha das Flores, Ilha de bom Jesus, Fernando de Noronha, Ilha das Cobras e a Ilha Trindade (SANTOS, 2007, p. 167) no Brasil; Peniche e Angra do Heroísmo (Ilha Terceira, Açores), em Portugal; Tarrafal (Ilha de Santiago, Cabo Verde), Tarrafal (Ilha de São Nicolau, Cabo Verde); e Ilha das Galinhas em Guiné-Bissau são as mais conhecidas. Para além de seu isolamento geográfico e também jurídico, por assim dizer, esses lugares compartilham uma identidade político-cultural e surgiram como fruto das mesmas práticas autoritárias afro-ibero-americanas e, principalmente, ainda hoje, estão sujeitos a uma mesma política do esquecimento ${ }^{6}$. É nossa hipótese que esses lugares se encaixem sob a rubrica daquilo que chamamos de Ilha-prisão - isto é, um local afastado dos centros de poder, cercado pelo mar, onde é possível instituir um regime político, jurídico e militar próprio que se caracteriza justamente pela ausência de garantias constitucionais ou institucionais que protejam sua população interna ${ }^{7}$, de modo a permitir, ou melhor ainda, de modo a implicar necessariamente na sua destruição.

Nesse contexto, se se tomar o caso concreto de Tarrafal, na costa africana, e da Ilha Grande, no litoral brasileiro, como centros irradiadores de uma pesquisa sobre a existência, funcionamento e significado dessas instalações car-

\footnotetext{
"Os termos "política do esquecimento" e "memória em perigo", ou ainda "memória em disputa", aparecem frequentemente nos trabalhos dos críticos e professores Roberto Vecchi, Margarida Calafate Ribeiro, Jaime Ginzburg e Francisco Foot Hardman. Baseando-se nas colocações de Walter Benjamin, no que diz respeito às relações entre rastro e narrativa, esses autores vão procurar descrever as realidades luso-brasileiras como um lugar de apagamento de vestígios. No caso das Ilhas-Prisão, isso se traduz de diversas maneiras. Não só sua memória é objeto de descaso institucional (lembremos, por exemplo, que, só em 2009, foi proposta a fundação de um museu nas antigas instalações de Tarrafal), como vem sendo sistematicamente reprimida ou mesmo denegada ao longo dos últimos trinta anos.

7 Nessa definição, nos inspiramos claramente em Giorgio Agamben que vai conceber o "estado de exceção" não como um regime alternativo e eventual ao estado de direito, mas como uma situação paradoxal na qual, através de um dispositivo legal, se abole o próprio estado de direito.
} 
cerárias, buscando recuperar através dos mais variados tipos de textos - entre os quais se destacam o livro Memórias do cárcere (1954) de Graciliano Ramos, os poemas de António Jacinto recolhidos em Sobreviver em Tarrafal de Santiago (1982) e a coletânea Antologia da Memória Poética da Guerra Colonial (2011), organizada por Roberto Vecchi e Margarida Calafate Ribeiro - a memória da violência e da destruição, bem como dos resíduos que tal experiência deixou na vida política, nas instituições oficiais e na vida cultural de seus países, vai ser possível (como, em outro trabalho, de maior fôlego, nos propomos realizar) ver como a consideração de uma Literatura Atlântica lança luz sobre um fenômeno de características similares que tomou corpo em diferentes nações e localidades, fazendo-se notável e deixando perceber a carga de horror que se esconde entre as fissuras da cultura e da história oficiais.

Não se trata de recolher apenas os escassos textos que, de um modo ou de outro, tenham procurado representar, em sentido estrito, a experiência individual e catástrofe coletiva que foram as ilhas prisões de Tarrafal, Ilha Grande e tantas outras. Como se trata aqui de elaborar novas leituras e novas narrativas do que sucedeu nesses lugares, a pesquisa irá se concentrar também em obras que abordem os momentos que precederam a instauração dessas prisões, ou ainda aqueles que só indiretamente fazem referência aos acontecimentos que aqui interessam, na medida em que é a partir dessa dispersa marginália que o objeto desta pesquisa - a memória dessas instituições e política soterradas pode ir surgindo.

Por fim, convém lembrar que muitos outros textos já cantaram ou testemunharam o encontro do homem com o mar, e que esse encontro já tem uma longa tradição no que diz respeito às culturas luso-afro-brasileiras. Nesse conjunto de referências se inserem desde textos fundadores até algumas das mais recentes produções contemporâneas em língua portuguesa. As marinas do Trovadorismo Galego-Português, os poemas de Viagem e Mar absoluto, de Cecília Meireles ou ainda os de Mar novo de Sophia de Mello Breyner Andresen, os romances Mar morto de Jorge Amado e A jangada de pedra, de José Saramago, são alguns exemplos. Dessa leva, muitos são os que retratam o mar sob o aspecto proposto aqui, ou seja, enfatizando o seu duplo potencial para unir ou separar povos através de relações múltiplas. Os lusíadas de Luís de Camões, Mensagem de Fernando Pessoa e, mais recentemente, As naus de Antônio Lobo Antunes, Nação crioula de Eduardo Agualusa e O outro pé da 
sereia de Mia Couto são alguns dos livros que fazem isso. No entanto, e apesar desse imenso patrimônio cultural construído em torno da presença fundamental do mar, ainda não foram construídos aparatos críticos e teóricos que procurem dar conta da dimensão histórica e política do imaginário marítimo, especialmente se se leva em consideração o seu potencial desierarquizante e mesmo anticolonial, uma vez que novas fronteiras e novas trocas simbólicas são continuamente desenhadas e redesenhadas sobre a sua superfície móvel e inquietante.

\section{Referências Bibliográficas}

ABDALA JR., Benjamin. Fronteiras múltiplas, identidades plurais: um ensaio sobre mesticagem e bibridismo cultural. São Paulo: Editora Senac, 2002.

AGAMBEN, Giorgio. Estado de excẹão. São Paulo: Boitempo, 2004.

AGUALUSA, Eduardo. Nação Crioula: a correspondência secreta de Fradique Mendes. Lisboa: Dom Quixote, 1997.

ALENCASTRO, Luiz Felipe de. O trato dos viventes: formação do Brasil no Atlântico Sul. São Paulo: Cia das Letras, 2000.

ANDRESEN, Sophia de Mello Breyner. Mar novo. Lisboa: Caminho, 2003.

ANTUNES, Antônio Lobo. As naus. Lisboa: Círculo de Leitores, 1988.

ARENAS, Fernando. Lusophone Africa: beyond Independence. Minneapolis: University of Minnesota Press, 2011.

BENJAMIN, Walter. Teses sobre o conceito de história. In Magia e técnica, arte e política. São Paulo: Brasiliense, 1994. Original alemão.

BAPTISTA, Abel Barros. Ideia de Literatura Brasileira com propósito cosmopolita. Revista Brasileira de Literatura Comparada, ABRALIC, São Paulo, 2010.

BAPTISTA, Abel Barros. Ensinar literatura brasileira em Portugal. In: O livro agreste: ensaio de curso de literatura brasileira. Campinas, UNICAMP, 2005 p. 19-39.

BERARDINELLI, Cleonice. O magistério da Literatura Portuguesa. In BUENO, Aparecida de Fátima [et al]. Literatura Portuguesa: história, memória e perspectivas. São Paulo: Alameda, 2007, p. 147-156.

CAMÕES, Luís de. Os lusíadas. Lisboa: Instituto Camões, 1989.

CARVALHAL, Tania Franco. Literatura comparada. São Paulo: Ática, 2004.

COUTINHO, Eduardo F; CARVALHAL, Tania Franco (Org.) Literatura comparada: textos fundadores. Rio de Janeiro: Rocco, 1994.

COUTO, Mia. O outro pé da sereia. Lisboa: Círculo de Leitores, 2006. 
FERREIRA, Roquinaldo. Cross-Cultural Exchange in the Atlantic World: Angola e Brasil During the Era of the Slave Trade. Cambridge: Cambridge University Press, 2012.

GOMES, Eugênio. Machado de Assis: influências inglesas. Rio de Janeiro: Pallas, 1996.

GINZBURG, Jaime. Crítica em tempo de violência. São Paulo: Edusp, 2012.

GINZBURG, Jaime. A interpretação do rastro em Walter Benjamin. In SEDLMAYER, Sabrina; GINZBURG, Jaime. Walter Benjamin: rastro, aura e história. Belo Horizonte: Editora UFMG, 2012.

HARDMAN, Francisco Foot. Trem fantasma: a modernidade na selva. São Paulo: Cia das Letras, 1988.

HOUAISS, Antônio; VILLAR, Mauro Salles. Grande Dicionário Houaiss da Lingua Portuguesa. Rio de Janeiro: Objetiva, 2008.

JACINTO, António. Sobreviver em Santiago de Tarrafal. Lisboa: INALD, 1982.

MEIRELES, Cecília. Viagem. In Poesia completa. Rio de Janeiro: Nova Aguilar, 1993.

MEIRELES, Cecília. Mar absoluto e outros poemas. Rio de Janeiro: Nova Fronteira, 1990.

PESSOA, Fernando. Mensagem. Lisboa: Edições Ática, 1970.

RAMOS, Graciliano. Memórias do cárcere. São Paulo: Record, 2008.

RUSSEL-WOOD, A.J.R. Sulcando os mares: um historiador do império português enfrenta a 'Atlantic History'. História, São Paulo, v. 28, n. 1, p. 17-70, 2009.

SANTOS, Irene Ramalho. Poetas do Atlântico: Fernando Pessoa e o modernismo anglo-americano. Belo Horizonte: UFMG, 2007.

SARAMAGO, José. A jangada de pedra. São Paulo: Cia. Das Letras, 1988.

VECCHI, Roberto. Excepção atlântica: pensar a literatura da guerra colonial. Porto: Afrontamento, 2010.

VECCHI, Roberto. Antologia da Memória Poética da Guerra Colonial. Porto: Afrontamento, 2011.

VECCHI, Roberto; RIBEIRO, Margarida. A memória poética da Guerra Colonial de Portugal na África. In SEDLMAYER, Sabrina; GINZBURG, Jaime. Walter Benjamin: rastro, aura e história. Belo Horizonte: Editora UFMG, 2012. 